\title{
A Numerical Study of Hovercraft Main Hull Structural Response Subjected to Shockwave from Underwater Explosion
}

\author{
Ching-Yu Hsu ${ }^{1}$, Cho-Chung Liang ${ }^{2}$, Tso-Liang Teng ${ }^{3, *}$, Hai-Anh Nguyen ${ }^{4}$ \\ ${ }^{1}$ Department Department of Marine Mechanical Engineering, ROC Naval Academy, Kaohsiung, Taiwan \\ ${ }^{2}$ Department of Mechanical and Automation Engineering, Da-Yeh University, Changhu, Taiwan \\ ${ }^{3}$ Department of Mechanical Engineering, Hsiuping University of Science and Technology, Taichung, Taiwan \\ ${ }^{4}$ Department of Mechanical Engineering, National Chiao Tung University, Hsinchu, Taiwan \\ *Corresponding author
}

\begin{abstract}
Hovercraft should be designed to survive in the extreme loading conditions, such as an underwater explosion (UNDEX). This paper used a finite element model based Zubrclass like LCAC (Air-cushioned landing craft) subjected to UNDEX to study dynamic responses of hovercraft main hull structure subjected to underwater explosion. A procedure which links together the finite element method (FEM) and AcousticStructure Coupling (ASC) method is developed. First, finite element model tests are conducted to verify and validate the propagation of shock response generated by an underwater explosive experiment of Ramajeyathilagam [3]. Second, finite element simulations of the hovercraft model subjected to UNDEX simulation that detonates of $9 \mathrm{~kg}$ of TNT were presented. The responses of main hull structure of the hovercraft model are also discussed. The numerical results show that besides global response, the main hull structure of hovercraft sustains severe local response especially is the main deck and skirt. The results could offer a valuable reference for hovercraft structure design.
\end{abstract}

Keywords-hovercraft; underwater explosions; acousticstructure coupling method; shockwave

\section{INTRODUCTION}

In this paper a full-scale hovercraft subjected to underwater explosion simulation is presented. Shock analyzes were conducted using a finite element based coupled Zubrclass like LCAC with a fluid model and an underwater explosion simulation that detonates $9 \mathrm{~kg}$ of TNT. Zubr-class hovercraft shock modeling and simulation has been performed. The investigation is accomplished via the validation of the Acoustic-Structure Coupling (ASC) method in an underwater explosion. Explosive shock waves damage is analyzed using ABAQUS and results are compared with those from analytical solutions, simulation or experimental results. The primary concern in naval engineering and offshore structure research is predicting how submerged structures are damaged by UNDEX. Numerical methods for analyzing submerged structures exposed to UNDEX shock loadings have been successfully implemented [1 10].

However, all of the aforementioned literature the UNDEX response was primarily studied for ships and submerged structures; little studies exist on dynamic responses of an air cushion vehicle (ACV). The response of a hovercraft Russian Zubr-Class model is the main concern within, including such aspects as dynamic behavior and structure response. This study developed procedures to study the dynamic response of hovercraft exposed to UNDEX, including such shock wave damage as applied Acoustic-Structure Coupling (ASC) method.

\section{THEORETICAL BACKGROUND}

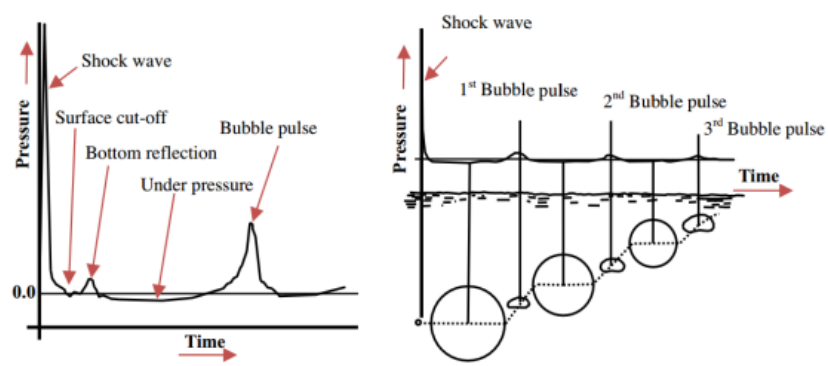

FIGURE I. PHENOMENON OF THE UNDERWATER EXPLOSION [1]

Generally the load caused by the shock wave is very high but the corresponding duration is very short (several milliseconds) showed as Figure 1. Empirical equations were determined to define the profile of the shock wave [11] and can be expressed as follows:

$$
\begin{gathered}
P(t)=P_{\max } e^{-t / \lambda} \\
P_{\max }=K_{1}\left(\frac{W^{1 / 3}}{R}\right)^{A_{1}} \\
\lambda=K_{2} W^{1 / 3}\left(\frac{W^{1 / 3}}{R}\right)^{A_{2}}
\end{gathered}
$$


$P(t)$ : the pressure profile of the shock wave (MPa);

$W$ : the weight of the explosive charge $(\mathrm{Kg})$

$R$ : the distance between explosive charge and target (m)

$P_{\max }$ : the peak pressure of the wave. (MPa)

$\lambda$ : the shock wave decay constant. (ms)

\section{NUMERICAL SIMULATION}

We apply the above method to the numerical studies of the potential damage to a hovercraft subjected to UNDEX. The overall length of the hovercraft is $57 \mathrm{~m}$. The beam of the hovercraft are $25.6 \mathrm{~m}$. The whole finite element model is shown as Figure 2.

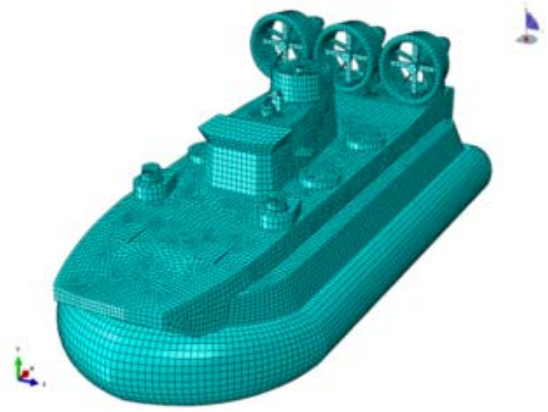

FIGURE II. FINITE ELEMENT MODEL OF ZUBR-CLASS

The numerical model includes 10 stiffeners and a keel arranging. The material and shape of the stiffeners and keel are used as box steel with the cross section and the specifications are lists in Table 1 . The body structure was constructed by aluminum (7075 Alloy), modeled using the average thickness technique of the hovercraft was $20 \mathrm{~mm}$, meanwhile the thickness of skirt part is $2.5 \mathrm{~mm}$ and made by coated fabric. There are 30,368 elements in this model, including 28,867 linear quadrilateral elements of type S4R shell elements, 688 B31 linear beam line elements and 813 linear triangular of type S3 elements with the element size is $0.5 \mathrm{~m}$. For simplicity, the light footprint pressure $3000 \mathrm{~Pa}$ is adopted to describe the cushion pressure when the fan speed is increasing further, pressure remains almost constant.

TABLE I. IMPACT SEVERITY LEVELS

\begin{tabular}{|c|c|c|c|}
\hline & Width (a) & Height $(\mathbf{b})$ & $\begin{array}{c}\text { Thickness } \\
(\mathbf{t} 1=\mathbf{t} 2=\mathbf{t} 3=\mathbf{t} 4=\mathbf{t})\end{array}$ \\
\hline Stiffener beam & $0.15 \mathrm{~m}$ & $0.1 \mathrm{~m}$ & $0.014 \mathrm{~m}$ \\
\hline Keel beam & $0.2 \mathrm{~m}$ & $0.12 \mathrm{~m}$ & $0.02 \mathrm{~m}$ \\
\hline
\end{tabular}

A spherical charge of $9 \mathrm{~kg}$ TNT was centered at the bottom of the hovercraft and located $10 \mathrm{~m}$ from the hovercraft surface. The Figure 3 depicts the external fluid (for shockwave numerical) was meshed with linear tetrahedral elements of type AC3D4 that consisted of 1,552,759 elements. The outer boundary of the external fluid was represented by a cylindrical surface with spherical ends. The characteristic radius of the outer boundary was $78.3 \mathrm{~m}$. The zero-pressure boundary condition is applied on the free surface of the flow field, and non-reflecting boundary condition is set on the other surfaces of the fluid model.

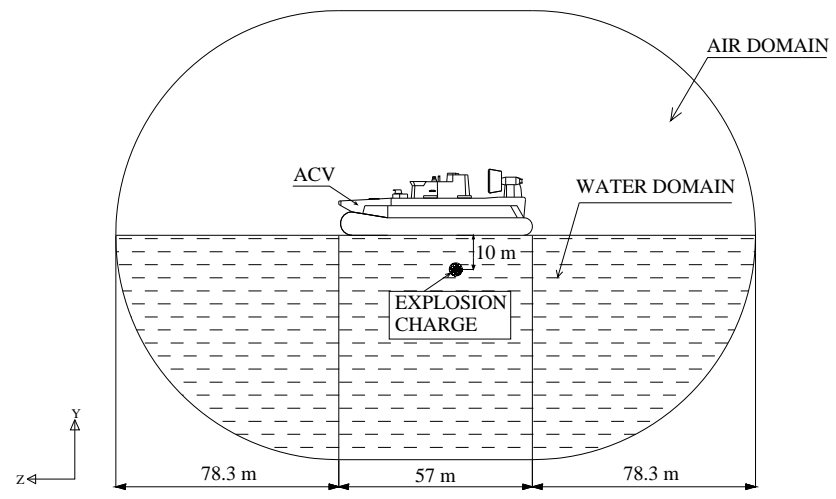

FIGURE III. PROFILE OF EXTERNAL FLUID MODEL

\section{RESUlTS AND DisCUSSION}

Figure 4 show a sequence of the responses of a hovercraft subjected to an underwater explosion shock wave at typical times. The filled contours figures illustrate the von Mises stress of the whole hovercraft model. It can be clearly observed that the yielding of materials under shock loading condition of the hovercraft model is mainly the local response. The shock load is transmitted through the fluid and reaches the skirt and main deck of hovercraft. At the time $\mathrm{t}=0 \mathrm{~ms}$, the shock loading with high pressure and has no influence on the hovercraft, so there is no response. From $\mathrm{t}=0.1 \mathrm{~ms}$ to $1.8 \mathrm{~ms}$, an obvious impact of shock wave onto the whole surface of the skirt; at $\mathrm{t}=2.4 \mathrm{~ms}$, damaged location is visible at the front of the skirt. At $\mathrm{t}=4.8 \mathrm{~ms}$, the main deck begins deformed under the influence of the load (pressure) and the middle part of the skirt that is located closest to the explosion being affected by explosions. At $\mathrm{t}=6.0 \mathrm{~ms}$, the vertical displacement of the whole structure reaches the maximum value, the main deck moves upwards with the underwater explosion loads. Fig.4 show that some locations of the underside of the skirt and the middle of the main deck also exhibit local response.

Figure 5 has shown that obvious local von Mises stress occur at the middle of skirt part and mid of main deck near close to the location of explosive charge. Fig. 6 indicates two types of value for von-Mises stress of hovercraft model at different locations from 0 to 0.006 second. Choose test points A1 (at the skirt) and A2 (at the main deck) have a significant local response of the peak von Mises stress (Fig.5). In general, most von Mises stress showed an increase with the locations in the underside of the skirt (A1) adjacent to the water sustain the biggest von Mises stress $4.3 \times 10^{8} \mathrm{~Pa}$, nearly 4.21 times of the von-Mises of $\mathrm{A} 2$ is $1.02 \times 10^{8} \mathrm{~Pa}$. For example, after a rise slowly from 0s to $0.004 \mathrm{~s}$, the von Mises stress at A1 reached a peak in 0.006 seconds of $4.34 .3 \times 10^{8} \mathrm{~Pa}$. Similarly, von Mises stress at A2 experienced the same trend from the lowest point to a peak of nearly $1.02 \times 10^{8} \mathrm{~Pa}$. That is because the skirt was damaged are more significantly compared with the main hull of the hovercraft. 


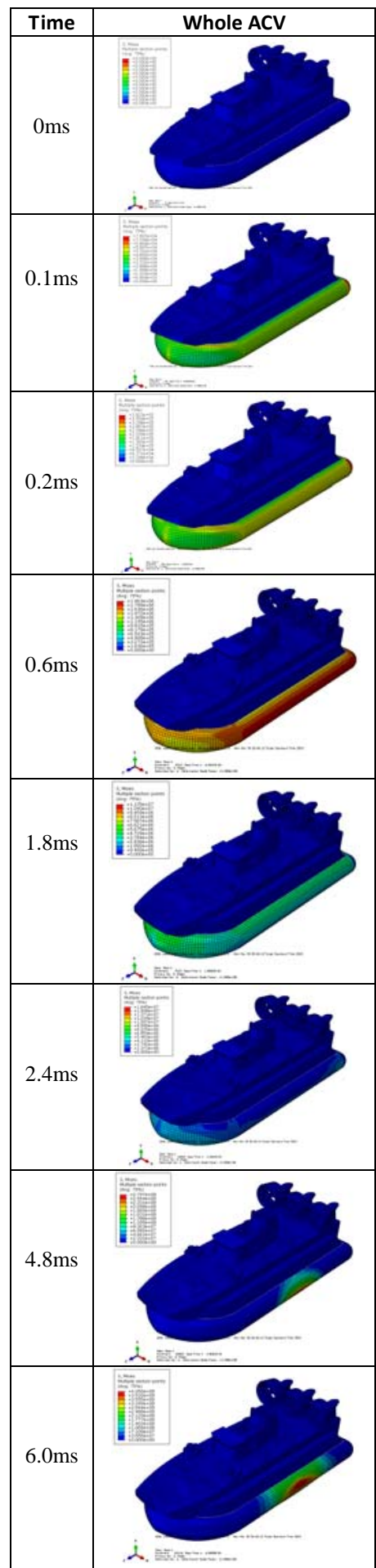

FIGURE IV. THE DYNAMIC RESPONSE HISTORY OF HOVERCRAFT MODEL UNDER THE LOAD OF SHOCK WAVE

To examine the response for the different locations in the body structure of hovercraft, several locations in the middle section A-A (the front of skirt part and control room of hovercraft (B1, B2, B3, B4), main deck (B5, B6, B7)) and section $\mathrm{B}-\mathrm{B}$ (P1, P2, P3, P4) throughout the hovercraft were chosen. As shown in Figure 7, due to the charge being located below the mid hovercraft, the peak accelerations, velocities and displacements of locations B1 and B2 are larger than other test points (B3, B4). For example, the peak accelerations of B1 is $699.62 \mathrm{~m} / \mathrm{s} 2(\sim 71.3 \mathrm{~g}$; with $\mathrm{g}=9.81$ is gravitational acceleration), approximately 1.55 and 25,629.15 times of that at the location B2 (450.69 m/s2 45.9g) and B3, B4 (0.02 $\mathrm{m} / \mathrm{s} 2 \sim 0.002 \mathrm{~g}$ ), respectively. For the velocity and displacement responses, it can be observed that the greatest velocity and displacement all occur at the B1, followed by the locations B2, and finally the location in front of ACV (B3, B4).

\section{CONCLUSION}

For this study, developed a procedure that links together the finite element and ASC method. The incident pressure from the explosive charge was determined according to the empirical equation by Cole. The results show that different portions of ACV will encounter different peak responses, depending on distance from the explosive charge. Through case studies, it is found that the high precision of the evaluation method. As a result, it can be applied to checking hovercraft's overall capacity against underwater explosion ultimate damage. The analytical results were offering a reference for evaluating the damage of hovercraft structure under the underwater explosion.

\section{REFERENCES}

[1] Y. S. Shin, "Ship shock modeling and simulation for far-field underwater explosion,” Computers \& Structures; 2004 (82), 2211-2219.

[2] K. Ramajeyathilagam, C. P. Vendhan, "Deformation and rupture of thin rectangular plates subjected to underwater shock," International Journal of Impact Engineering, 2004, 30 (6), 699-719.

[3] R. Kalavalapally, R. Penmetsa and R.Grandhi, "Multidisciplinary optimization of a lightweight torpedo structure subjected to an underwater explosion,” Finite Elements in Analysis and Design, 2006 (43), 103-111.

[4] C. C. Liang, Y. S. Tai, "Shock response of a surface ship subjected to noncontact underwater explosions,” Ocean Engineering, 2006 (33), 748772.

[5] C. F. Hung, B. J. Lin, J. J. Hwang-Fuu, P. Y. Hsu. "Dynamic response of cylindrical shell structures subjected to underwater explosion," Ocean Engineering, 2009,36 (8), 564-577.

[6] J. Qiankun, D. Gangyi, "A finite element analysis of ship sections subjected to underwater explosion,” Impact Engineering, 2011 (38), 558566.

[7] Z. Zong, Y. Zhao, H. Li, "A numerical study of whole ship structural damage resulting from close-in underwater explosion shock," Marine Structures, 2013 (31), 24-43.

[8] N. Zhang, Z. Zong, W. P. Zhang, "Dynamic response of a surface ship structure subjected to an underwater explosion bubble," Marine Structures, 2014 (35), 26-44.

[9] H. Wang, X. Zhu, Y. S. Cheng, J. Lin, "Experimental and numerical investigation of ship structure subjected to close-in underwater shock wave and following gas bubble pulse,” Marine Structures, 2014 (39), 90-117.

[10] S. W. Gong, B. C. Khoo, "Transient response of stiffened composite submersible hull to underwater explosion bubble," Composite Structures, 2015 (122), 229-238.

[11] R. H. Cole, Underwater explosion. New Jersey. Princeton University Press, 1948. 


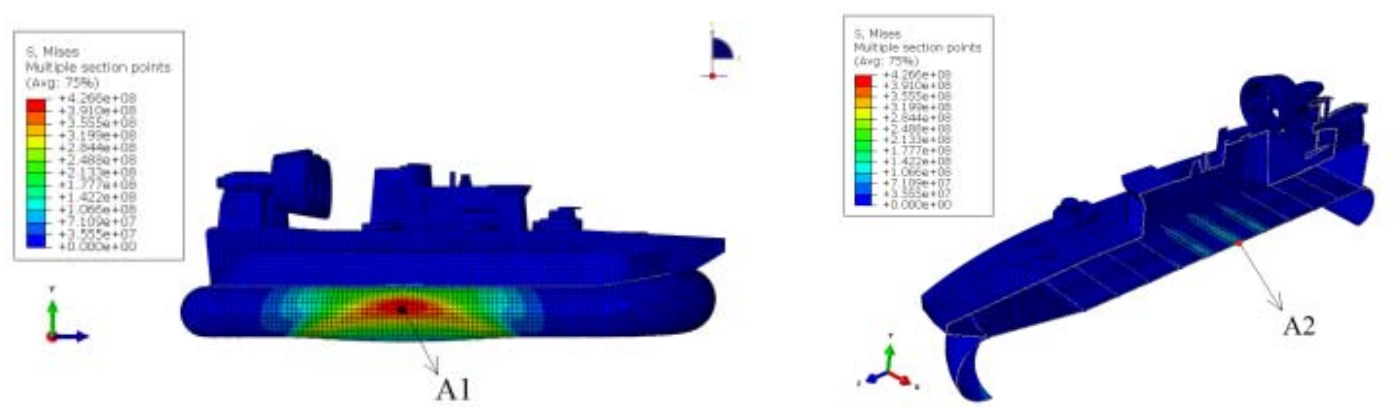

FIGURE V. VON MISES STRESS OF HOVERCRAFT MODEL
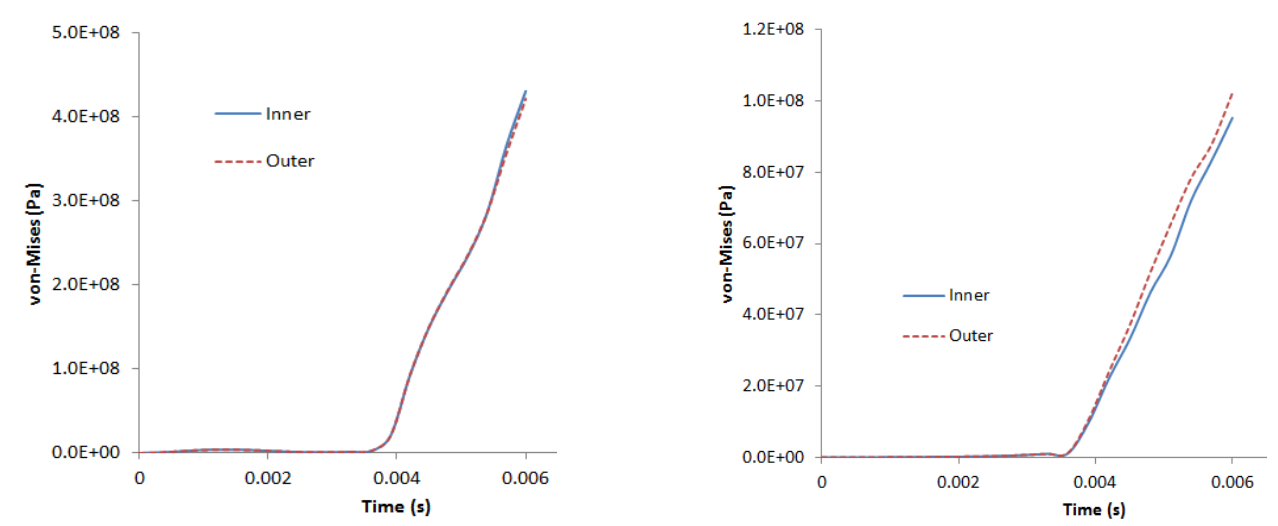

FIGURE VI. TIME HISTORIES OF VON-MISES STRESS OF POINT A1 AND A2 ON HOVERCRAFT MODEL

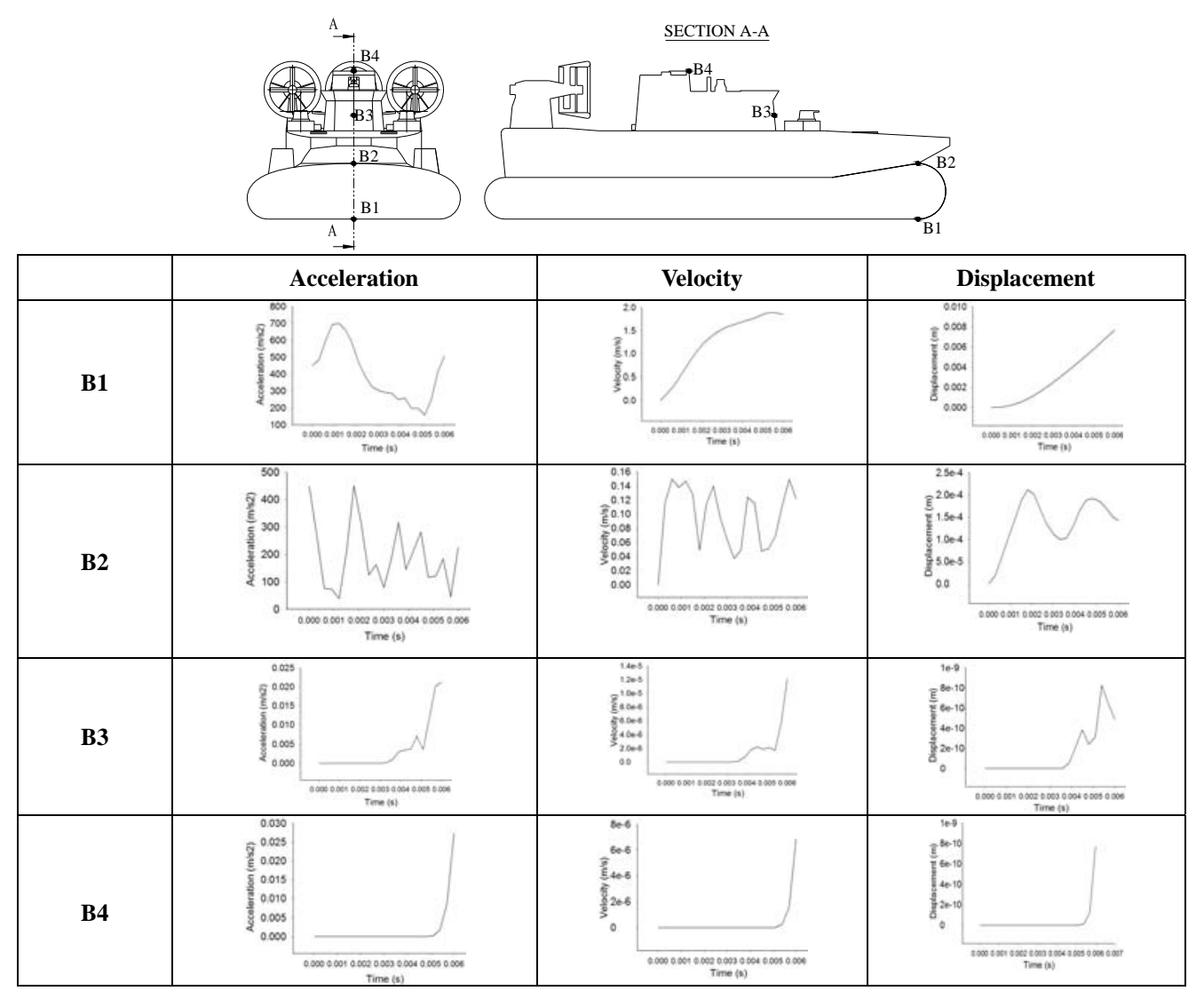

FIGURE VII. RESPONSE OF THE HOVERCRAFT AT DIFFERENT TEST POINTS (B1,B2,B3,B4) 